\title{
Properties of Acrylonitrile Butadiene Rubber Modified with Acrylate Monomers and Oligomers Using Gamma Irradiation
}

\author{
Khaled F. El-Nemr", Hamdi R. Mohamed and Issa M. Mousaa \\ Radiation Chemistry Department, National Center for Radiation Research and \\ Technology, Atomic Energy Authority, Cairo, Egypt.
}

\begin{abstract}
CRYLONITRILE butadiene rubber (NBR) is commonly used as oil and fuel resistant in industrial applications. This study is carried out to investigate the effect of adding some acrylate monomers and oligomers that was used by constant concentration, namely $(0.02 \mathrm{~mol}$ $/ 100 \mathrm{~g}$ of rubber) to improve the physical and mechanical properties of (NBR) reinforced by $30 \mathrm{phr}$ carbon black and mixed in a rubber rol mill, exposed to gamma radiation (doses from 25 to $150 \mathrm{kGy}$ ). The results indicated that the acrylate monomers increase the tensile strength (TS) at lower doses up to $50 \mathrm{kGy}$, while the oligomers increase the TS at higher doses more than $50 \mathrm{kGy}$. On the other hand, the physical properties such as soluble fraction, swelling ratio and crosslinking density showed dependence on the specific unsaturation (SU) of monomer and oligomer. The thermal stability of the composites tested by thermogravimetric analysis (TGA) recorded comparable values except NBR modified by urethane diacryalte (UDA) have the lowest value.
\end{abstract}

Keywords: Acrylonitrile butadiene rubber, Mechanical properties, Monomers, Oligomers, Thermal stability.

\section{Introduction}

Acrylonitrile-butadiene rubber (NBR), commonly as known nitrile rubber, is an unsaturated copolymer of acrylonitrile and butadiene and commonly considered as the workhorse of the industrial and automotive rubber products. Acrylonitrile-butadiene rubber (NBR) has been commercially available for more than 50 years because of its moderate cost, excellent resistance to oils, fuels and greases, easy processibility and very good resistance to swelling by aliphatic hydrocarbons. About $80 \%$ of NBR produced is used for machinery and automobile industry (Brydson, 1988 and Yasin et al., 2002). The property of the nitrile rubber is dependent on the acrylonitrile content which determines the oil resistance of the rubber (Chakraborty et al., 2007 and Balachandran el al., 2010, 2012).

For commercial applications, NBR requires additional ingredients, which include reinforcement fillers, plasticizers, antioxidants, processing aids and crosslinking agents (Tan, 1993). The effect of different curing systems including sulfur, dicumyl peroxide, dicumyl peroxide/coagent and radiation/coagent on the mechanical and physico-chemical properties of acrylonitrile butadiene rubber (NBR) was studied by El Nemr (2011).

The major obstacle in radiation crosslinking of NBR is the need of high irradiation doses, which are a prerequisite to achieve the desired crosslinking density in NBR however, at high irradiation doses the mechanical properties are adversely affected due to the degradation induced by radiation (Basfar el al., 1999 and Clavreul \& Pellegrin, 2001). Appropriate polyfunctional monomers (PFMs) in polymer matrix can be used to obtain the desired crosslinking density at lower irradiation doses (Tabata el al., 1991; Youssef el al., 1993 and Ahmed \& Ruimin, 1999).

Furthermore, many authors (Youssef et al., 1993; Ahmed et al., 2000 and Xu et al., 1995) reported that PFMs are useful, as an antioxidant set, to obtain the optimum mechanical properties at lower dose levels. These PFMs form a network structure with polymeric materials at a lower dose, because of its higher reactivity (Tabata el al., 1991) and the resulting structure, are useful for improving the mechanical properties as well as

\#Corresponding author email: hradi_99@yahoo.com

DOI: 10.21608/ejrsa.2018.1749.1019

C2017 National Information and Documentation Center (NIDOC) 
the thermal stability (Thomine el al., 2007). The effect of adding NBR rubber to polyether sulfone/ epoxy blend has been investigated (Horiuchi el al., 1994).

The effect of multifunctional monomers or oligomers (MFM/O) additives on electron beam (E-beam) radiation induced crosslinking of poly (styrene-block-isoprene/butadiene-block-styrene) (SIBS) was studied. Ten types of MFM/O were investigated, including trimethylolpropane trimethacrylate (TMPTMA), trimethylolpropane triacrylate (TMPTA), triallyl cyanurate (TAC), polybutadiene diacrylate (PB-diacrylate), ethylene glycoldimethylacrylate(EGDMA), butylene glycol dimethacrylate (BGDMA), 1,2-polybutadiene. The effects of MFM/O concentration and E-beam radiation dose on the properties of SIBS were studied including tensile strength, elongation-atbreak, modulus, gel content, equilibrium swelling and crosslinking density. TMPTA significantly improved the tensile modulus and crosslinking density of SIBS. SIBS with TMPTMA and TMTPMA with inhibitor showed a 50\% increase in the tensile strength. The solubility of MFM/O in SIBS was also investigated by a selective swelling method. The MFM/O was found to be soluble in both phases of SIBS. The viscosity of SIBS with methacrylate type MFM/O was stable at $200^{\circ} \mathrm{C}$ (Wu \& Soucek, 2016).

Sinceno available published studies concerning the effect of acrylate oligomers, such as epoxy and urethane acrylate as crosslinking agents on NBR rubber under ionizing radiation have been found, the present work aims at establishing a comparative study to describe the discrepancy in the effect of adding acrylate monomer, on the one hand, and acrylate oligomer, on the other, to improve the physical and mechanical properties of NBR rubber under variant doses of $\gamma$-irradiation.

\section{Experimental}

\section{Materials}

Acrylonitrile butadiene rubber (NBR) of Europrene N3345, was supplied from Enichem company Inc, Italy, having (acrylonitrile content-34\%, Mooney viscosity (ML $(1+4)$ at $\left.100^{\circ} \mathrm{C}-46\right)$. Compounding ingredients, i.e., Zinc oxide, stearic acid are of commercial grade. 1,2- dihydro.2,2,4-trimethyl quinoline (TMQ) as antioxidant was obtained from Intatrade Chemicals GmbH, Germany. Carbon black N 375, supplied by Hebei LongHao Chemical Technology Co., China. The oligomers used are Bisphenol A diglycidyl ether diacrylate $(\mathrm{EDA})$ viscosity $=8.0$ poise $\left(\right.$ at $60^{\circ} \mathrm{C}$ ), volatile content $=1.0 \%$, specific gravity $=1.17 \mathrm{gml}^{-1}$ (at $25^{\circ} \mathrm{C}$ ) and aliphatic urethane diacrylate (UDA), viscosity $=13$ poise $\left(\right.$ at $\left.25^{\circ} \mathrm{C}\right)$, volatile content $=$ $2.0 \%$, specific gravity $=1.13 \mathrm{gml}^{-1}\left(\right.$ at $\left.25^{\circ} \mathrm{C}\right)$ were supplied by Cytec Surface Specialties, Drogenbos, Belgium. Two reactive monomers tripropylene glycol diacrylate (TPGDA), molecular formula $\mathrm{C}_{15} \mathrm{H}_{24} \mathrm{O}_{6}$ density $1.03 \mathrm{~g} / \mathrm{ml}$ at $25^{\circ} \mathrm{C}$ and assay $>98 \%$ and 1, 6 hexanediol diacrylate (HDDA), molecular formula $\mathrm{C}_{12} \mathrm{H}_{18} \mathrm{O}_{4}$, with density of $1.01 \mathrm{~g} / \mathrm{ml}$ at $25^{\circ} \mathrm{C}$ and assay $>98 \%$ were obtained from Cytec Surface Specialties, Drogenbos, Belgium.

\section{Compounding and curing}

The preparation of NBR composites, at different compositions (Table 1) was done on a two-roll mill; NBR after milling on rubber mill, ingredients were successively added as follows: TMQ, ZnO, Stearic acid and carbon black. Finally, the constant concentration of PFMs and oligomers used in this investigation was $0.02 \mathrm{~mol} / 100 \mathrm{~g}$ of rubber for comparison. The mixing process was carried out for about $15 \mathrm{~min}$ at room temperature to uniformly disperse carbon black into NBR. After mixing the samples, they were hot pressed at about $160^{\circ} \mathrm{C}$ under $10 \mathrm{MPa}$ for $5 \mathrm{~min}$ into sheets of suitable thickness and size for analysis.

\section{Gamma irradiation}

The devolved composites were submitted to gamma irradiation (gamma cell type $4000 \mathrm{~A}$, India), in air, at room temperature and in ambient humidity. The radiation doses were 25, 50, 100 and $150 \mathrm{kGy}$ at a dose rate of $\approx 2.8 \mathrm{kGy} / \mathrm{h}$. Irradiation was carried out at the National Center for Radiation Research and Technology, Atomic Energy Authority, Cairo, Egypt.

\section{Mechanical measurements}

Five individual dumbbell-shaped specimens were cut out from the sheets using a steel die of standard width, $4 \mathrm{~mm}$. The minimum thickness of the test specimens was determined by gauge graduated to one hundredth of the mm. A bench mark of $1.5 \mathrm{~cm}$ was made on the working part of each test specimen. The ultimate tensile strength and elongation at break point were determined at crosshead speed $500 \mathrm{~mm} /$ min on a rubber tensile testing machine, Mecmesin, United Kingdom. Type of multiTest 25-I, provides high capacity force measurements up to $25 \mathrm{kN}$, with full programming capability.

\section{Soluble fraction (SF)}

Soluble fraction measurement was carried out as follows: The samples of the irradiated 
TABLE 1. Formulation of rubber composites mixes.

\begin{tabular}{llc}
\hline Ingredient & Function & Concentration (phr*) \\
\hline NBR & Rubber matrix & 100 \\
TMQ & Antioxidant & 1 \\
ZnO & Activator & 5 \\
Stearic acid & Processing aid & 1 \\
Carbon black N375 & Reinforced filler & 30 \\
Monomers \& Oligomers & Sensitizing agent & $0.02 \mathrm{~mol} / 100 \mathrm{~g}$ of rubber \\
\hline
\end{tabular}

rubbers of about $0.2 \mathrm{~g}$ were accurately weighed $\left(\mathrm{W}_{\mathrm{o}}\right)$ and placed in a special stainless grids. The grids containing the samples were transferred to a special round bottle flask $2 / 3$ filled with toluene for heating under reflux for $24 \mathrm{~h}$. After extraction, the samples were lifted and stranded for $2 \mathrm{~h}$ in a fuming hood before drying. After extraction and drying, the samples were weighed in air to the nearest $1 \mathrm{mg}\left(\mathrm{W}_{1}\right)$, then dried to constant weights in dry oven at $50^{\circ} \mathrm{C}$. The soluble Fraction can be calculated as follows:

$$
\mathrm{SF}=\mathrm{W}_{\mathrm{o}}-\mathrm{W}_{1} / \mathrm{W}_{\mathrm{o}}
$$

where: $\mathrm{Wo}_{\mathrm{o}}=$ Original weight of the sample, $\mathrm{W}_{1}=$ Final weight of the sample after extraction.

Volume fraction of rubber in swollen gel

The volume fraction of rubber in a swollen gel $\left(\mathrm{V}_{\mathrm{r}}\right)$ was calculated according to the following equation:

$$
\mathrm{V}_{\mathrm{r}}=\frac{\left(\mathrm{W}_{1}-\mathrm{W}_{\mathrm{o}} \mathrm{f}\right) / \delta_{\mathrm{r}}}{\left(\mathrm{W}_{1}-\mathrm{W}_{\mathrm{o}} \mathrm{f}\right) / \delta_{\mathrm{r}}+\left(\mathrm{W}_{2}-\mathrm{W}_{1}\right) / \delta_{\mathrm{s}}}
$$

where: $\mathrm{W}_{\mathrm{o}}=$ original weight, $\mathrm{W}_{1}=$ deswollen weight, i.e, weight after extraction and drying, $\mathrm{W}_{2}=$ weight after swelling, $\mathrm{f}=$ weight fraction of insoluble components, $\delta_{\mathrm{r}}$ and $\delta_{\mathrm{s}}$ the density of rubber and solvent respectively.

\section{Determination of cross-link density (v)}

The equilibrium swelling in acetone was used to calculate the cross-link density, which is the number of network chain density by applying the Flory-Rehner equation as follows:

$$
v=-1 / \mathrm{V}_{\mathrm{s}}\left[\frac{\ln \left(1-\mathrm{V}_{\mathrm{r}}\right)+\mathrm{V}_{\mathrm{r}}+\chi_{1} \mathrm{~V}_{\mathrm{r}}^{2}}{\mathrm{~V}_{\mathrm{r}}^{1 / 3}-\mathrm{V}_{\mathrm{r}} / 2}\right]
$$

where, $\mathrm{V}_{\mathrm{s}}$ is the molar volume of the solvent, $\mathrm{V}_{\mathrm{r}}$ is the volume fraction of rubber in swollen gel and $\chi_{1}$ is the polymer-solvent interaction parameter which is equal to 0.351 for NBR in acetone.

Swelling ratio $(Q)$

The degree of swelling ratio (Q) was calculated and expressed in terms of its reciprocal of volume fraction of rubber in the swollen gel as follows (Boonstra, 1979):

$$
\mathrm{Q}=\mathrm{V}_{1} / \mathrm{V}_{\mathrm{o}}=1 / \mathrm{V}_{\mathrm{r}}
$$

where $V_{1}$ is the volume of swollen rubber, $V_{0}$ the volume of unswollen rubber, and $\mathrm{V}_{\mathrm{r}}$ is the volume fraction of rubber in the swollen gel.

\section{Thermogravimetric analysis measurements}

The thermogravimetric analysis (TGA) technique was applied using a TG-50 instrument from Shimadzu, Japan, for testing the thermal behavior of samples. The heating was carried out at temperature range from room temperature to $600^{\circ} \mathrm{C}$ with a heating rate of $10^{\circ} \mathrm{C} / \mathrm{min}$ under nitrogen gas atmosphere. The weight of samples ranged from 3 to $5 \mathrm{mg}$.

\section{Results and Discussion}

\section{Mechanical properties}

One of the most obvious effects brought about by irradiation on the rubber compounds due to their crosslinking/degradation is their tensile strength (Nicholas, 1990). Figure 1 shows the effect of $\gamma$-radiation dose on the tensile strength of NBR samples containing different monomers and oligomers. The tensile strength values of NBR with HDDA and TPGDA monomers sharply increased with increasing the radiation dose up to $25 \mathrm{kGy}$, then levelled off or slightly increased respectively by increasing irradiation dose up to $100 \mathrm{kGy}$, and finally levelled off or decreased at $150 \mathrm{kGy}$. The presence of diacrylate double bonds in HDDA and TPGDA account for augmenting the crosslinking density with NBR via radiationinduced free radicals formed. Beyond $25 \mathrm{kGy}$, 
consistent stability due to the domination of the crosslinking process took place within NBR containing two monomers. At higher doses; higher than $100 \mathrm{kGy}$, the TS slightly decreased as a result of radiation-induced degradation process in carbon chains. On the other hand, at low radiation doses the NBR containing UDA and EDA oligomers records lower TS values when compared to NBR containing monomers. Lower crosslinking density occurred due to inter/intramolecular hydrogen bonds among the -OCONH- groups in the high molecular weight of UDA oligomer (Fenfen \& Wenfang, 2010). Meanwhile, in the case of EDA oligomer, the presence of two benzene rings resists the impact of radiation, thus decreasing crosslinking density. However, at higher radiation doses, above $50 \mathrm{kGy}$, the crosslinking density grows and the TS values start to increase up to consistent state and then the tensile strength values tend to decrease as a result of scission in the polymeric chains eliciting lower strength (Yasin et al., 2002 and Nigrey, 2000).

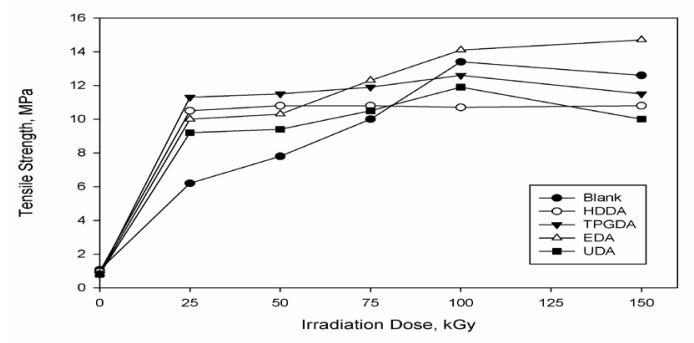

Fig. 1. Tensile strength for NBR cpmposites modified by monomers and oligomers

Figure 2 shows the effect of $\gamma$-radiation dose on the elongation at break $\left(\mathrm{E}_{\mathrm{b}}\right)$ of NBR samples containing different monomers and oligomers. It is obvious that $\mathrm{E}_{\mathrm{b}}$ maximum value was recorded for NBR containing UDA and the minimum value for NBR containing EDA. This may be ascribed to the flexibility of urethane acrylate oligomer chains and adversely the rigidity and brittleness of epoxy acrylate oligomer chains (Kumar et al., 2008). The $\mathrm{E}_{\mathrm{b}}$ values of all rubber compounds sharply increased with increasing the $\gamma$-radiation dose up to $25 \mathrm{kGy}$, then the elongation at break decreased with dose icreasing for all samples as a result of excessive crosslinked structures produced in the sample matrix. The latter prevent the structural organization during drawing, bringing about a reduction in the internal chain mobility and elongation till leveling off. This observation further supports the explanation provided for the swelling ratio and crosslinking density behavior.

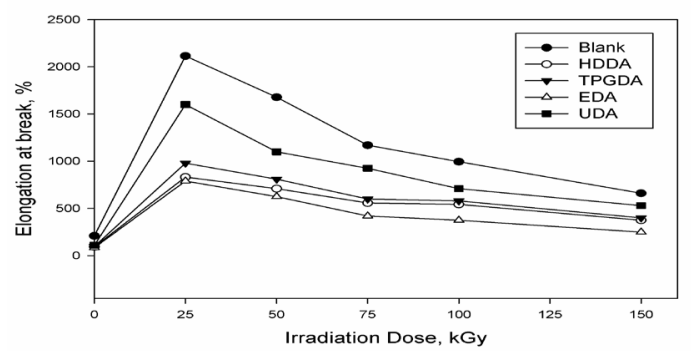

Fig. 2. Elongation at break $E_{b} \%$ for $N B R$ composites modified by monomers and oligomers.

Determination of the physico-chemical properties

The crosslinking density of polymers without sensitizers is linearly related to the absorbed dose (Yunshu et al., 1998):

$$
1 / \mathrm{M}_{\mathrm{c}}=\left(\mathrm{A}+\mathrm{KC}_{\mathrm{o}}\right) \mathrm{D}
$$

whereas; the crosslink density $1 / \mathrm{M}_{\mathrm{c}}$ was calculated from the swelling behavior according to Flory swelling theory (Flory, 1953), $\mathrm{M}_{\mathrm{c}}$ is the mean molecular weight between crosslinking points, $\mathrm{A}$ and $\mathrm{K}$ are constants $\mathrm{D}$ is the dose in $\mathrm{kGy}, \mathrm{A}$ $+\mathrm{KC}$, represent the slope of the lines in Fig. 3 . The figure shows that after the addition of PFMs and oligomers to NBR rubber, the crosslinking density linearly increased with the absorbed dose in the order: HDDA exhibits the almost results for crosslinking density, followed by UDA, meanwhile the control sample gave the lowest crosslinking density value.

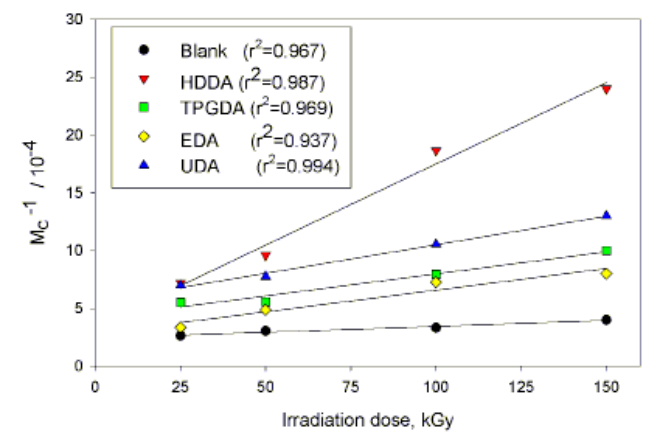

Fig. 3. Calculated crosslinking density of NBR modified by monomers and oligomers according to Flory equation.

As the initial content of the PFMs and oligomers is already known, the values of $\mathrm{K}$ according to the applied equation can be calculated for each sensitizer and ploted against specific saturation (SU), as represented in Fig.4. From this figure, it can be seen that the $\mathrm{K}$ value increases with increasing SU values, emphasizing that $\mathrm{SU}$ value is an important factor to be considered when choosing sensitizers 
for radiation crosslinking. The higher the SU value is, the faster the crosslinking density increases with the absorbed dose (Yunshu et al., 1998). As shown from Table 2, the results indicated the order of crosslink density increase as follows: HDDA > UDA $>$ TPGDA $>$ EDA.

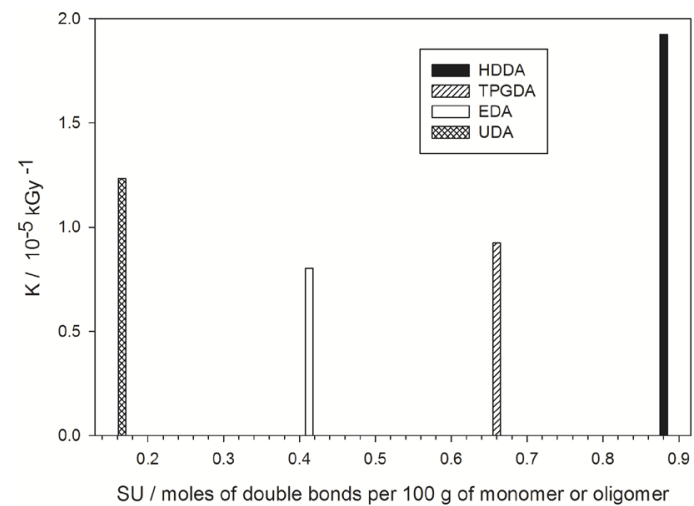

Fig. 4. Effect of specific unsaturation (SU) of monomers and oligomers on their sensitizing efficiency.

TABLE 2. PFMs and oligomers used in this study.

\begin{tabular}{llccc}
\hline $\begin{array}{l}\text { Trade } \\
\text { name }\end{array}$ & Chemical name & $\mathbf{M}_{\mathrm{w}}$ & $\mathbf{F}$ & $\mathbf{S U}$ \\
\hline HDDA & $\begin{array}{l}\text { 1,6 hexandiol } \\
\text { diacrylate }\end{array}$ & 103.95 & 2 & 1.924 \\
TPGDA & $\begin{array}{l}\text { Tripropyleneglycol } \\
\text { diacrylate }\end{array}$ & 216.36 & 2 & 0.9244 \\
EDA & Epoxy diacrylate & 242.13 & 2 & 0.8026 \\
UDA & Urethane diacrylate & 162.21 & 2 & 1.233
\end{tabular}

$\mathrm{F}$ is Functionality, number of double bonds in each monomer or oligomer molecules; $\mathrm{SU}$ is specific unsaturation, moles of double bonds $/ 100 \mathrm{~g}$ of monomer or oligomer.

Determination of the physico-chemical properties, such as SF and Q, of radiation vulcanized NBR was carried out in acetone. Figure 5 shows that the values of SF decrease with increasing the dose for all composites enhanced by different sensitizers. On the other hand, it can be seen that $\mathrm{SF}$ decreases in the order control NBR $>$ EDA $>$ TPGDA $>$ UDA $>$ HDDA. The results obtained are in agreement with the data obtained before for the crosslink density. It is possible to correlate the values of $\mathrm{V}_{\mathrm{r}}$ presented in Fig. 6 with crosslinking density for NBR composites in Fig. 7. As the calculated values for $\mathrm{V}_{\mathrm{r}}$ give indication of crosslinking level of rubber vulcanizate and measure the ability of the reinforcing filler (Sunity \& Sadhan, 1982), V values also confirm the data formerly obtained forthe crosslinking density. Determination of $\mathrm{Q}$ was carried out in acetone at equilibrium situation, as shown in Fig. 8. It has been recognized that restriction of the swelling is related to filler-polymer interaction. This factor is almost constant in the present case; the only variable is the radiation dose, where the crosslinking density of NBR composites increased in the order shown before.

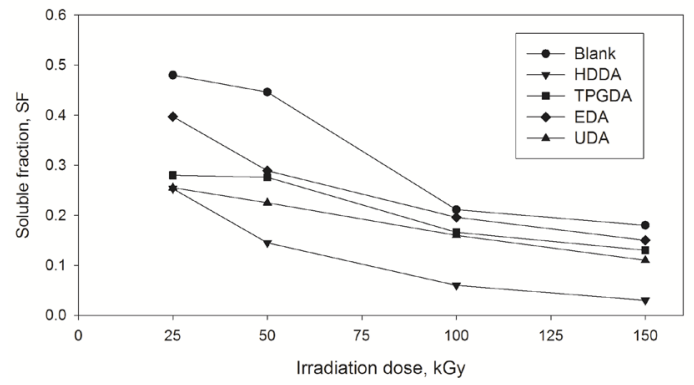

Fig. 5. Soluble fraction of NBR modified by monomers and oligomers.

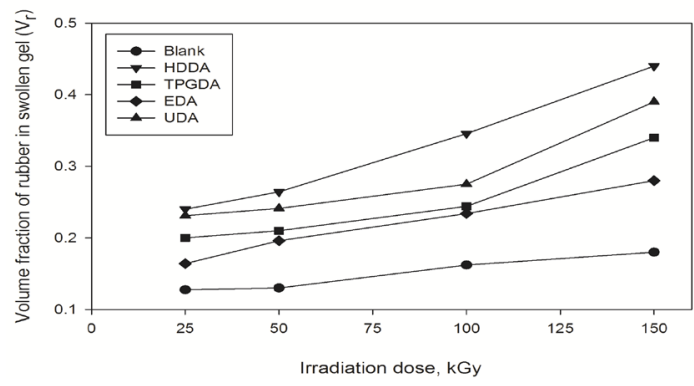

Fig. 6. $\mathrm{V}_{\mathrm{r}}$ for $\mathrm{NBr}$ modified by monomers and oligomers.

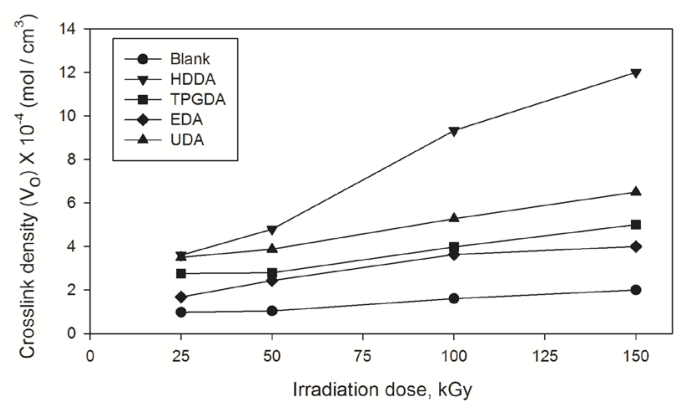

Fig. 7. Crosslink desnity for $\mathrm{NBr}$ modified by monomers and oligomers.

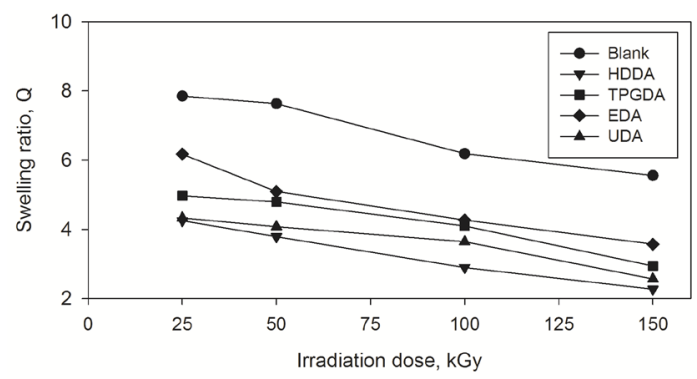

Fig. 8. $Q$ for NBr modified by monomers and oligomers.

Egypt. J. Rad. Sci. Applic. Vol. 30, No.2 (2017) 
Depending on the above outcomes, the behavior of TS can be explained by the physico-chemical results. HDDA and UDA, as shown before in Fig. 4, exhibit a good sensitizing efficiency, however, the TS of the crosslinked product demonstrates the lowest values. On the contrary, the TS values of the crosslinked NBR by TPGDA and EDA are markedly high in spite of their low sensitizing efficiency as described by their K values. This may be accounted for the different molecular structures of monomers and oligomers, that link to polymer chains and form crosslinking bonds. Thus, the mechanical properties of the sensitized crosslinked polymers are not only related to the crosslinking density, but also closely related to the category and structure of the implemented sensitizing agents (Yunshu et al., 1998).

\section{Thermogravimetric analysis (TGA)}

Thermogravimetric analysis is widely used as a tool to study the degradation of different polymeric materials at a wide range of temperature.

The Thermogravimetric data presented in Fig. 9, Show the variation in the weight remaining percentage (WR \%) as a measure of the weight loss for NBR enhanced with 1,6-hexandiol diacrylate (HDDA), tripropylene glycol diacrylate (TPGDA), epoxy diacrylate (EDA), and urethane diacrylate (UDA), and irradiated at $50 \mathrm{kGy}$ as a function of heating temperature. From Fig. 9, it can be seen that except for the case of UDA, the thermograms obtained are characterized by being single stepped indicating that one distinct degradation process took place on elevating the temperature. On rising the temperature higher than $\sim 400-525{ }^{\circ} \mathrm{C}$, the $\mathrm{WR} \%$ values show a sudden drop, thereafter, slowly decrease up to $600{ }^{\circ} \mathrm{C}$. The sudden drop occurring in $\mathrm{WR} \%$ may be attributed to the decomposition of the main constituent of the composite, namely the rubber matrix. Compared with the blank sample, no significant shift to a higher temperature was detected with the incorporation of HDDA, TPGDA, and EDA in the rubber matrix. Meanwhile, in the case of loading with UDA, the sample undergoes two-step degradation. In the first step, peak temperature, around $260^{\circ} \mathrm{C}$ may be attributed to the degradation of urethane segments (Seo et al., 2010), and the subsequent second degradation temperature peak around $400^{\circ} \mathrm{C}$ is due to the rubber chain degradation. Table 3 shows the temperature at different weight loss $\%$ of NBR rubber blank and NBR enhanced with HDDA, TPGDA, UDA and EDA, that irradiated at $50 \mathrm{kGy}$. The data obtained from this table provide support to the data obtained before, as discussed in Fig. 9

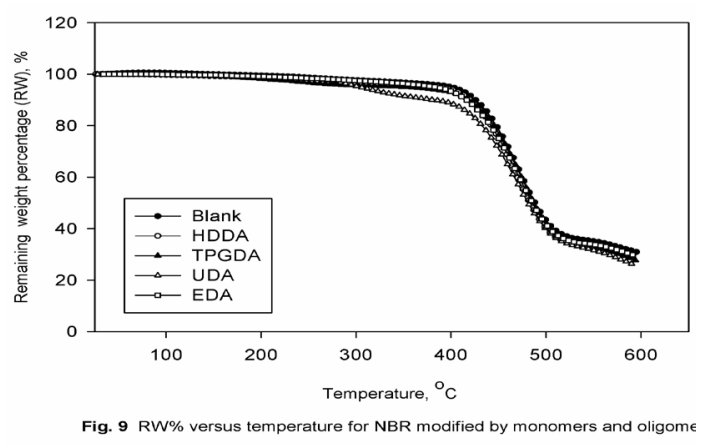

Fig. 9. RW\% vesus temperature for $\mathrm{NBr}$ modified by monomers and oligomers.

TABLE 3. Temperatures at different weight losses for NBR rubber loaded with $30 \mathrm{phr}$ carbon black and enhanced with HDDA, TPGDA, UDA and EDA.

\begin{tabular}{lcccccc}
\hline & \multicolumn{3}{c}{$\begin{array}{c}\text { Decomposition } \\
\text { temperature at } \\
\text { different weight loss } \\
\text { Sample type }\end{array}$} & $\begin{array}{c}\left.{ }^{\circ} \mathbf{C}\right) \\
\end{array}$ & $\mathbf{T}_{\max 1}$ & $\mathbf{T}_{\max 2}$ \\
\cline { 2 - 4 } & $\mathbf{1 0 \%}$ & $\mathbf{2 0 \%}$ & $\mathbf{5 0 \%}$ & & \\
\hline Blank & 425 & 445 & 490 & - & 465 \\
NBR+ HDDA & 420 & 443 & 485 & - & 470 \\
NBR + & 420 & 445 & 487 & - & 470 \\
TPGDA & & & & & \\
NBR + UDA & 380 & 435 & 480 & 295 & 465 \\
& & & & & \\
NBR + EDA & 415 & 430 & 485 & - & 467 \\
\hline
\end{tabular}

Figure 10 shows the variation in the rate of decomposition $(\mathrm{dw} / \mathrm{dt})$ as a function of heating temperature of the above mentioned samples and irradiated up to $50 \mathrm{kGy}$. From this figure, it can be seen that the thermograms obtained for NBR blank and NBR enhanced with HDDA, TPGDA, and EDA show one peak maxima at about $\sim 470$ ${ }^{0} \mathrm{C}$. Moreover, the addition of UDA led to two peaks maxima at $\sim 295^{\circ} \mathrm{C}$, due to the degradation of urethane segments as mentioned above and $\sim 465^{\circ} \mathrm{C}$, due to the decomposition of rubber chain degradation .

\section{Conclusions}

The tensile strength values of NBR modified by HDDA and TPGDA monomers sharply increased with increasing the radiation dose up to $50 \mathrm{kGy}$. Meanwhile, at a higher radiation dose, above 50 kGy, NBR modified by EDA or UDA oligomers, 
demonstrated crosslinking density increases and the TS values tended to increase until equilibrium by a dose of $100 \mathrm{kGy}$. At any radiation dose, the $\mathrm{E}_{\mathrm{b}}$ of NBR modified by UDA exhibited the highest values, meanwhile NBR modified by EDA gave the lowest $\mathrm{E}_{\mathrm{b}}$ values. The physical properties, such as SF, Q and crosslinking density were found to depend on SU. The thermal stability of NBR modified by HDDA, TPGDA and EDA showed comparable values, while modification by UDA resulted in the lowest figures.

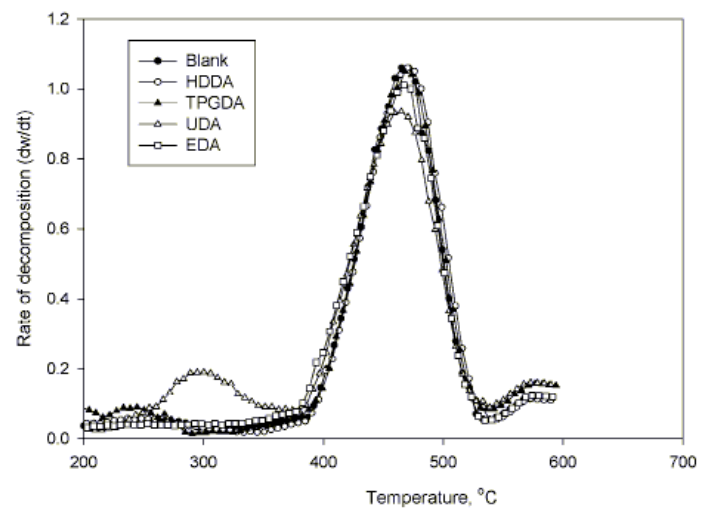

Fig. 10. Rate of decomposition for NBr modified by monomers and oligomers.

\section{References}

Ahmed, S. and Ruimin, Z. (1999) "Development of Formulations of Polyethylene Based FlameRetardant, Radiation-Resistant Wires". IAEA TECDOC-1062. Vienna, Austria, pp.129-139.

Ahmed, S, Basfar, A.A. and Abdel Aziz, M.M. (2000) Comparison of thermal stability of sulfur, peroxide and radiation cured NBR and SBR vulcanizates. $J$ Polym Degrad Stab. 67, 319-23.

Balachandran, M., Devanathan, S., Muraleekrishnan, R. and Bhagawan, S. (2012) Optimizing properties of nanoclay-nitrile rubber (NBR) composites using face centred central composite design. Mater. Des. 35,854 .

Balachandran, M., Stanly, L.P., Muraleekrishnan, R. and Bhagawan, S.S. (2010) Modelling NBR layered silicate nanocomposites: A DoE approach. J. Appl. Polym. Sci. 118, 3300.

Basfar, A.A., Abdel-Aziz, M.M. and Mofti, S. (1999) Stabilization of c-radiation vulcanized EPDM rubber against accelerated aging. J. Polym. Degrad. Stab. 66, 191-197.

Boonstra, B.B. (1979) Role of particulate filler in elastomer reinforcement: A review; Polymer, 20, 691.

Brydson, J.A. (1988) "Rubbery Materials and their Compounds". Elsevier Applied Science, Amsterdam, pp. 187-205.
Chakraborty, S., Bandyopadhyay, S., Ameta, R. Mukhopadhyay, R. and Deuri, A.S. (2007) Application of FTIR in characterization of acrylonitrile- butadiene rubber (nitrile rubber). Polym. Test. 26, 38.

Clavreul, R. and Pellegrin, L. (2001) Lifespan prediction of EPR seals under gamma radiation. J. Polym. Test, 20, 769-770.

El-Nemr, K. F. (2011) Effect of different curing systems on the mechanical and physico-chemical properties of acrylonitrile butadiene rubber vulcanizates, Materials and Design, 32, 3361-3369.

Fenfen, Bao and Wenfang, Shi (2010) Synthesis and properties of hyperbranched polyurethane acrylate used for UV curing coatings. Progress in Organic Coatings, 68, 334-339.

Flory, P.J. (1953) "Principles Physics and Chemistry". Cornell University Press, Ithaca, NY.

Horiuchi, S., Street, A.C., Ougizawa, T. and Kitano, T. (1994) Toughening behavior of rubber- modified thermoplastic polymers involving very small rubber particle. II. Rubber cavitation behaviour in polyvinyl chloride/methacrylate butadiene-styrene grapht copolymer (MBS) blends. Polymer, 35, 4750-4759.

Kumar, V.Y.K., Bhardwaj, N.K., Goel, S., Francis, K.A., Dubey, C.V., Chaudhari, K.S.S. and Sarma, S.S. (2008) Coating characteristics of electron beam cured Bisphenol A diglycidyl ether diacrylate-coaliphatic urethane diacrylate resins. Surface \& Coatings Technology, 202, 5202-5209.

Nicholas, P. (1990) "Product Design and Testing of Polymeric Materials". Cheremisinoff. , Dekker, New York. USA

Nigrey, P.J. (2000) Comprehensive testing to measure the response of butyl rubber to hanford tank waste simulant. Sandia Report.

Seo, J.C., Jang, E.S., Song, J.H., Choi, S., Khan, S.B. and Han, K. (2010) Preparation and properties of poly (urethane acrylate) films for ultravioletcurable coatings, J. Appli. Polym. Sci. 118, 2454-2460.

Sunity, K. Chakraborty and Sadhan, K.De. (1982) Epoxy-resin-cured carboxylated nitrile rubber. $J$. Appli. Polym. Sci. 27, 4561-4576.

Tabata, Y., Ito, Y. and Tagawa, S. (1991) "CRC Handbook of Radiation Chemistry". CRC Press, USA.

Tan, E.H., Wolff, S., Haddeman, M., Grewatta, H.P. and Wang, M.J. (1993) Filler-elastomer interactions. part IX. Performance of silicas in polar elastomers rubber. Chem. Technol. 66, 594-604.

Thomine, M., Degrangea, J.M., Vigier, G., Chazeau, L., 
Pelletier, J.M., Kapsa, P., Guerbe, L. and Dudragne, G. (2007) Study of relations between viscoelasticity and tribological behaviour of filled elastomer for lip seal application. J Tribo. Int. 40, 405-411.

$\mathrm{Wu}$, J. and Soucek, M.D. (2016) The effect of multifunctional monomers/oligomers additives on electron beam radiation crosslinking of poly (styrene-block-isoprene/butadiene-block-styrene) (SIBS). Radiat Phys. Chem. 119, 55-63.

Xu, Y., Yoshii, F. and Makuuchi, K. (1995) Radiation crosslinking of chlorinated poly (Isobutyleneco-Isoprene) with polyfunctional monomers. $J$. Macromol. Sci. A: Pure Appl. Chem. 32, 1801-1808.
Yasin, T., Ahmed, S., Yoshii, F. and Makuuchi, K. (2002) Radiation vulcanization of acrylonitrilebutadiene rubber with polyfunctional monomers. $J$. React. Funct. Polym. 53, 173-181.

Youssef, H.A., Yoshii, F., Makuuchi, K., Elmiligity, A.A. and Abdel Aziz, M.M. (1993) Physical properties of styrene- butadiene rubber radiation vulcanized with functional monomers. Makromol. Rep. A, 30, 315-326.

Yunshu, Xu, Yibei, Fu, Yoshi, F. and Makuuchi, K. (1998) Sensitizing effect of polyfunctional monomers on radiation crosslinking of polychloroprene. Radiat. Phys. Chem. 53, 669-672.

\section{دراسة خواص مطاط النتريل المعالج بالإثعاع بإستخدام مونيمرات وأوليجمرات الأكريلات خالد فاروق النمر و حمدى راضى محمد و عيسى محمد محمد موسى الإسى

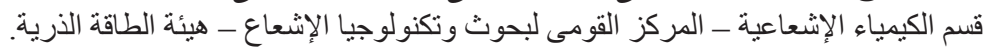

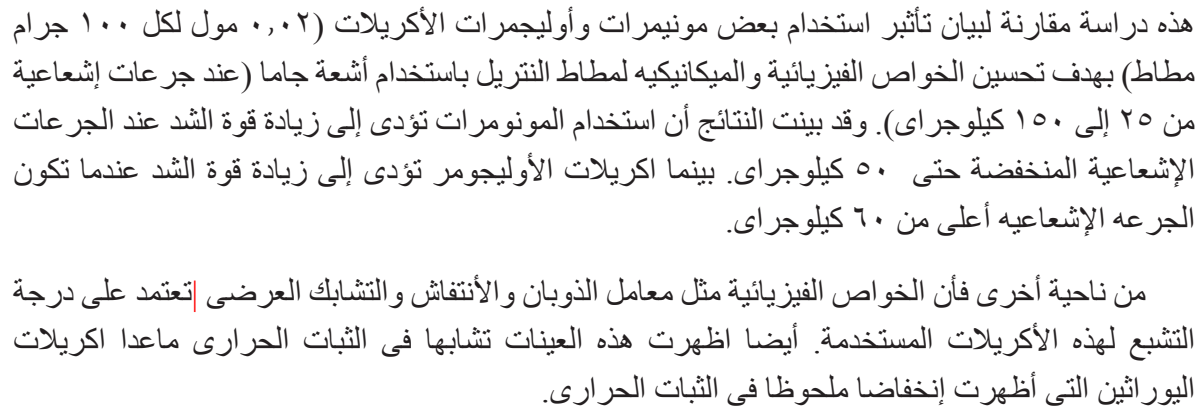

